\title{
Electrochemical Oxidation of Toluene on Glassy Carbon Electrodes in Organic Medium
}

\author{
Luis F. D'Elia, ${ }^{*}$ R. Ortíz \\ ${ }^{1}$ Universidad de los Andes, Facultad de Ciencias, Departamento de Química, Laboratorio de \\ Electroquímica, Mérida 5101, Venezuela
}

Received 4 March 2005; accepted in revised form 6 October 2005

\begin{abstract}
The electro-oxidation of toluene in $0.1 \mathrm{M} \mathrm{But}_{4} \mathrm{NPF}_{6}+\mathrm{CH}_{3} \mathrm{CN}$ solutions on glassy carbon electrodes was studied using electrochemical and spectroelectrochemical techniques. Toluene electro-oxidation yields an electrochemical inactive film on the electrode surface. In situ Fourier Transformed Infrared (FTIR) studies suggest the formation of a polymeric film, as the main product, on the surface. Depending on the experimental time scale toluene transformation is a complex reaction that could involve adsorption processes, pure charge transfer reaction and couple chemical reactions. Additions of small quantities of water to the electrolyte cause a cathodic displacement of the oxidation peak potential; in other words, the electro-oxidation reaction is favoured.
\end{abstract}

Keywords: electrochemical oxidation, toluene, organic medium, glassy carbon, in situ FTIR.

\section{Introduction}

Through the years, the electrochemical oxidation of organic compounds has been extensively studied for the treatment of industrial wastewater streams [1,2], organic electrosynthesis [3,4] and others [4]. More recently, hydrocarbons electro-oxidation studies have gained more attention, as they can be used as fuel in solid oxide fuel cells (SOFC) systems for power generation $[5,6]$.

Toluene electro-oxidation has been performed at polycrystalline platinum surfaces using acetonitrile and different supporting electrolytes [7,8]. For all cases, the electrochemical reaction yields a polymeric film deposited on the electrode surface. Due to the electrolyte decomposition, toluene does not react

\footnotetext{
* Corresponding author. E-mail address: delialf@pdvsa.com Present address: Petróleos de Venezuela (PDVSA)-Intevep; Gerencia General de Refinación e Industrialización; Gerencia Técnica de Refinación; Apartado 76343; Caracas 1070-A; Venezuela.
} 
when a mixture of alcohol and sulphuric acid is used as electrolytic medium [9]. However, it produces carbon dioxide and water when the reaction is carried out in sulphuric acid [10].

The electrochemical reaction has been also tested on $\beta-\mathrm{PbO}_{2}, \mathrm{Fe}(\mathrm{III})-\beta-\mathrm{PbO}_{2}$ and $\mathrm{Bi}(\mathrm{V})-\beta-\mathrm{PbO}_{2}$ electrodes, yielding benzoic acid as unique product [11]. In previous work, by using theoretical modelling, we have shown that the electrooxidation of toluene on metal oxides strictly depends on the adsorption interaction between the oxide surface and the aromatic molecule $[12,13]$. For this reason, $\mathrm{TiO}_{2}$ is slightly active [12], nevertheless $\mathrm{CeO}_{2}$ and $\mathrm{V}_{2} \mathrm{O}_{5}$ are totally inactive surfaces for the electro-oxidation of toluene $[12,13]$.

There has been published a lot of reports on the electro-oxidation of toluene on different surfaces in organic medium; however, no one shows a detail study of the fundamental remarks of the charge transfer reaction on carbon surfaces. In this work, toluene was electro-oxidized at glassy carbon in $0.1 \mathrm{M} \mathrm{But}_{4} \mathrm{NPF}_{6}+$ $\mathrm{CH}_{3} \mathrm{CN}$ medium. Voltammetric experiments suggest that toluene is oxidized at $2280 \mathrm{mV}$ vs. $\mathrm{Ag} / \mathrm{AgCl}$ producing a polymeric film on the electrode surface. Electrochemical evidences indicate that toluene transformation is a complex process and is strongly influenced by the water content of the electrolytic medium. By using in situ FTIR, the products were followed monitoring the C-C and $\mathrm{C}=\mathrm{C}$ (extended aromatic system) bonds apparition at the normalized infrared spectra.

\section{Experimental}

\section{Chemicals}

The electro-oxidation of toluene (Riedel de Haën, HPLC grade) was performed in $0.1 \mathrm{M} \mathrm{But}_{4} \mathrm{NPF}_{6}$ (Aldrich, $99.9 \%$ ) $+\mathrm{CH}_{3} \mathrm{CN}$ (Aldrich, HPLC grade, water content around $3 \mathrm{mM}$ ) solutions.

\section{Cells and electrodes}

The electrochemical studies were performed at $(25.0 \pm 0.1){ }^{\circ} \mathrm{C}$ in a two compartment cell. A glassy carbon (GC) disc (Carbone Lorraine, Type I) was used as working electrode. The reference electrode ( $\mathrm{Ag} / \mathrm{AgCl}, \mathrm{KCl}$ saturated) was separated from the working compartment by a Luggin capillary. A platinum gauze (Aldrich, $99.99 \%$ ) was employed as counter electrode. The in situ FTIR experiments were carried out using the typical cell reported elsewhere [14], employing a calcium fluoride $\left(\mathrm{CaF}_{2}\right)$ optical window.

Just prior to be used, the $\mathrm{GC}$ discs were polished to mirror appearance using $\mathrm{Al}_{2} \mathrm{O}_{3}$ powder of different grades, down to $0.05 \mu \mathrm{m}$. Electrodes were rinsed with ultrapure water $\left(18 \mathrm{M} \Omega . \mathrm{cm}^{-1}\right)$ and ultrasonically cleaned in water for 10 minutes.

\section{Instrumentation}

Electrochemical measurements were carried out with an Autolab 20 potentiostat, controlled with a General Purpose Electrochemical System software (GPES) version 4.8. In situ FTIR instrumental set up was described in a previous work [3]. 


\section{Results and discussions}

\section{Electrochemical studies}

a) Fundamental aspects of the electrode process

Repetitive cycle voltammograms of a GC disc in toluene containing solution (Fig. 1) show two important features: $(i)$ an oxidation peak located at about 2280 $\mathrm{mV}$ and (ii) an anodic peak current density decreasing with increasing the number of cycles. After ten cycles, a dark green deposit is easily observed on the electrode surface, which could explain the GC surface deactivation.

The initial activity of the GC surface could be achieved using mechanical and electrochemical methods. Mechanical cleaning is an unpractical method because involves the surface polishing after each experiment. On the other hand, the electrochemical treatment offers a practical and efficient in situ way to clean the electrode surface.

Fig. 2 shows how the potential pre-treatment $\left(\mathrm{E}_{\mathrm{pt}}\right)$ affects the current density ratio $\left(\mathrm{j}_{\text {p.ap }} / \mathrm{j}_{\mathrm{p}}\right) . \mathrm{j}_{\text {p.ap }}$ and $\mathrm{j}_{\mathrm{p}}$ are defined as the anodic peak current density after the potentiostatic pre-treatment and the anodic peak current density without any pretreatment, respectively. The potentiostatic pre-treatment was applied to the electrode in toluene containing solutions after completing one cycle of potential. Both current densities values were measured at the first sweep of the cycle voltammogram.

It may be noted that the initial GC activity is gradually achieved with increasing the applied potential. However, after applying $4000 \mathrm{mV}$ the peak current density ratio is bigger than one and the oxidation peak potential $\left(E_{p}\right)$ is displaced +20 $\mathrm{mV}$. At potentials higher than $3500 \mathrm{mV}$, both film degradation and glassy carbon surface reactions take place $[15,16]$. It was also shown that this behaviour is not changed or influenced by the time application of the potential pulse; any change was recorded at times longer than 30 seconds.

The electrochemical oxidation of toluene is controlled by the charge transfer reaction (Fig. 3a), as it is suggested by the linear relationship of $j_{p}-v^{1 / 2}$ with an intercept different to zero. The electrodic reaction also shows the typical behaviour for an irreversible electrode process (Fig. 3b) [17]. The relation $E_{p}-\log$ $v$ shows two slopes (Fig. 3c), which indicate that the global reaction must involve kinetic complications or composite processes [18]. 


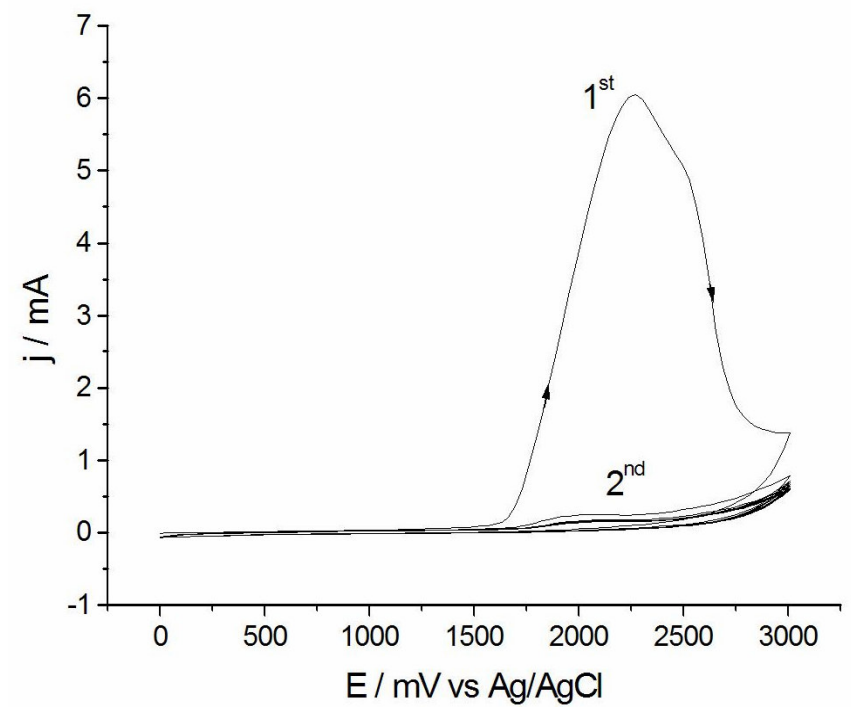

Figure 1. Repetitive cyclic voltammograms of a GC disc in $\mathrm{N}_{2}$ saturated $50 \mathrm{mM}$ Toluene $+0.1 \mathrm{M} \mathrm{But}_{4} \mathrm{NPF}_{6}+\mathrm{CH}_{3} \mathrm{CN}$ between 0 and $3000 \mathrm{mV}$. Sweep rate, $100 \mathrm{mV} . \mathrm{s}^{-1}$. Geometric area of the electrode: $0.78 \mathrm{~cm}^{2}$.

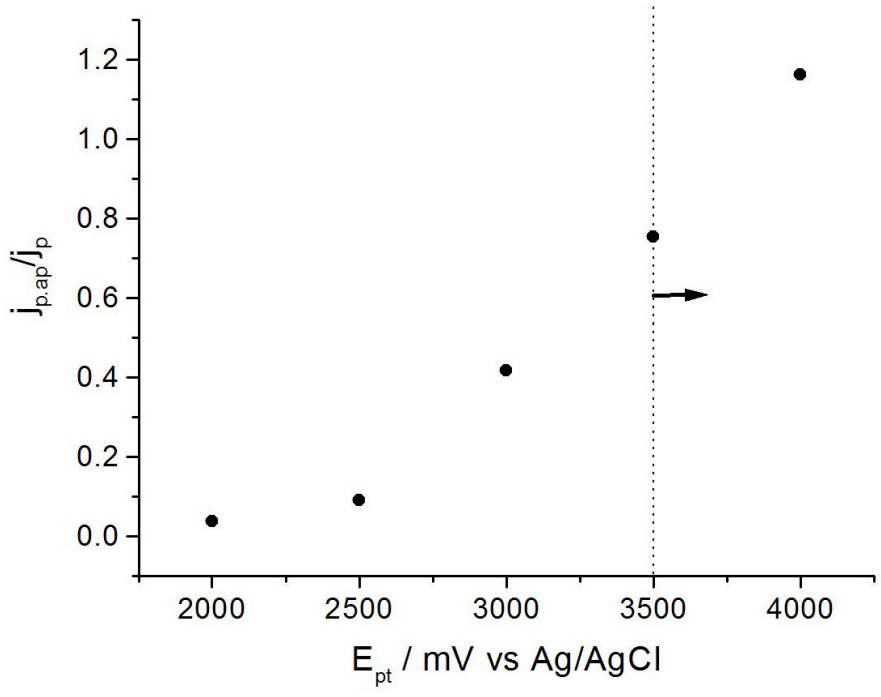

Figure 2. Effect of the pre-treatment potential $\left(\mathrm{E}_{\mathrm{pt}}\right)$ on the regeneration of the glassy carbon activity. The potential pre-treatment was applied for 30 seconds.

Fig. 4a shows that the electrochemical reaction is followed by a chemical reaction [17]; and the complexity of the global reaction is confirmed plotting $\mathrm{j}_{\mathrm{p}}$ as a function of $v$ (Fig. 4b). Any charge transfer reaction that is controlled by an adsorption process should show a linear relationship between $\mathrm{j}_{\mathrm{p}}$ and $\mathrm{v}$ with an intercept equal to zero [17]; however, in our case the intercept is different to zero (Fig. 4b). This fact confirms that the electrode reaction is a complex process that involves different steps at different time scale reaction. 

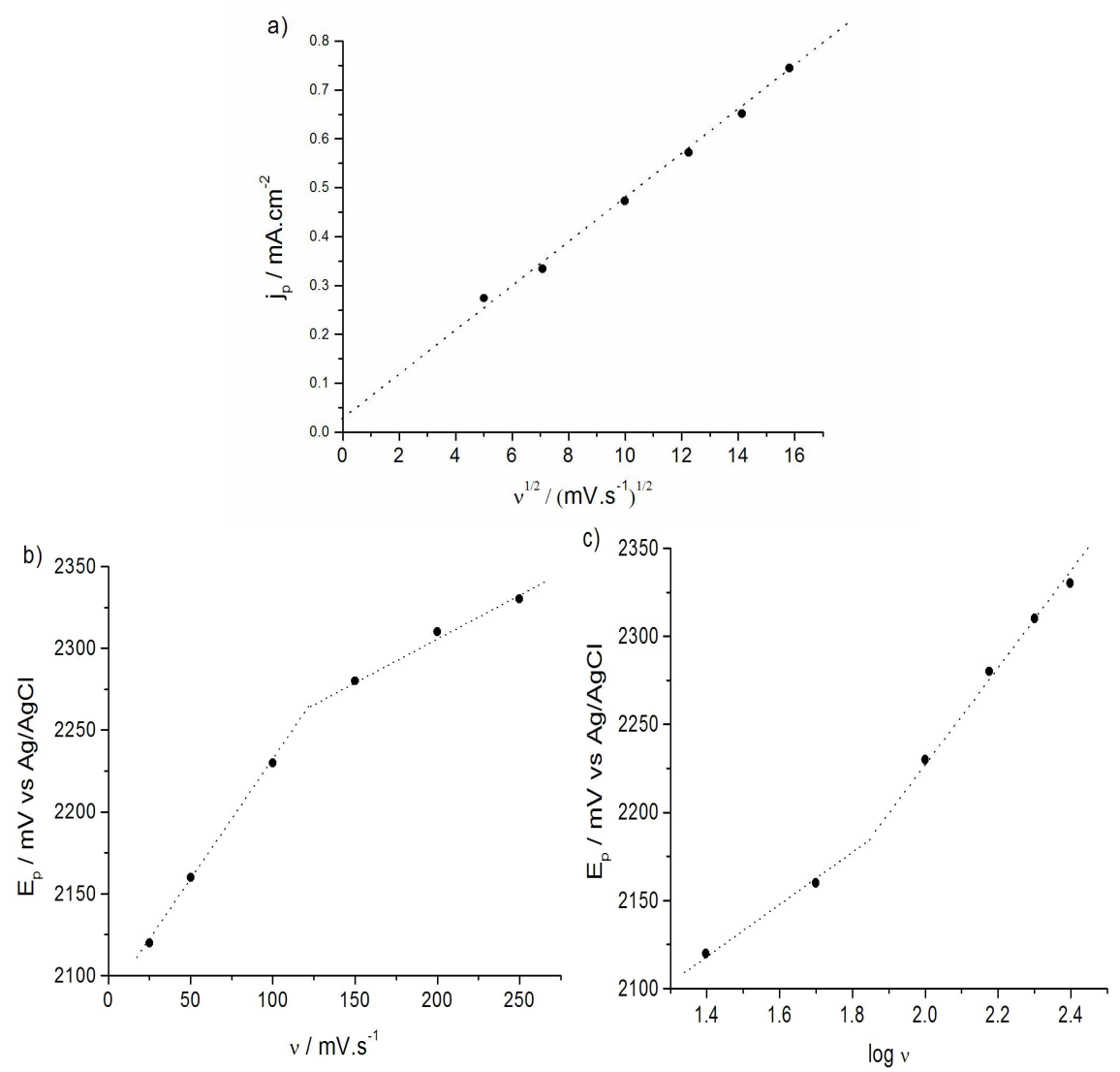

Figure 3. a) Anodic peak current density $\left(j_{p}\right)$-square root of the sweep rate $\left(v^{1 / 2}\right)$ relationship; b) variation of $E_{p}$ with $v$; c) $E_{p}-\log v$ relationship.
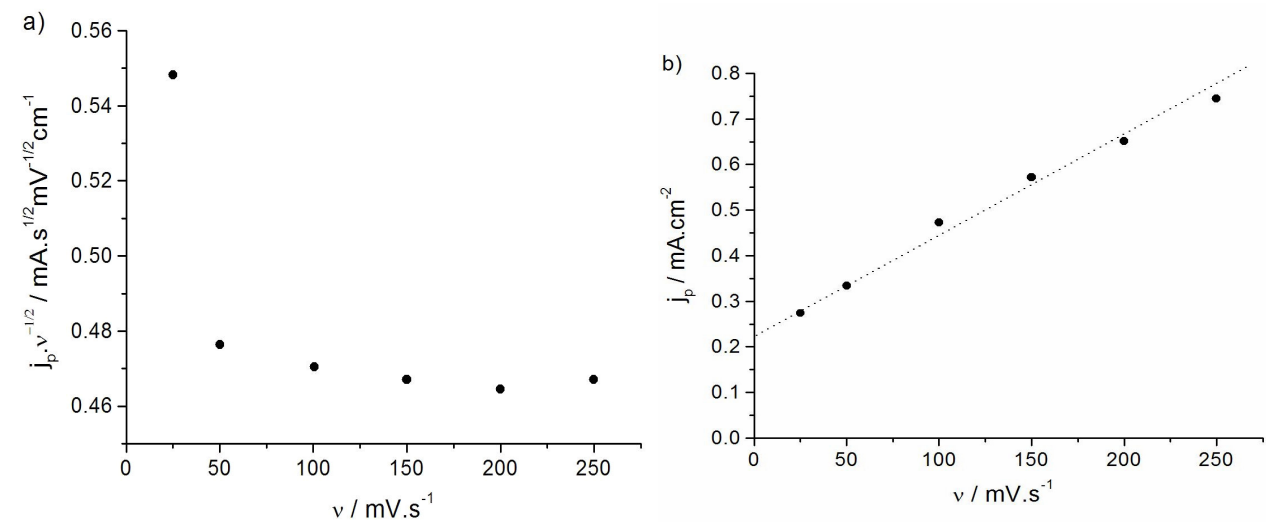

Figure 4. a) Current density function $\left(\mathrm{j}_{\mathrm{p}} \cdot v^{-1 / 2}\right)-v$ relationship; $\left.b\right) \mathrm{j}_{\mathrm{p}}-v$ relationship.

It may be stated, from the fundamental electrochemical studies, that the features of the global reaction depend on the experimental time scale. At low sweep rates the reaction is controlled by pure charge transfer reaction, but at high sweep rates the adsorption of toluene defines the electrochemical transformation.

Fig. 5a shows the relationship between the peak current density and the molar concentration of toluene $\left(\mathrm{C}_{\mathrm{T}}\right)$. It clearly indicates, under the experimental conditions, that an adsorption process controls the charge transfer reaction. At concentrations higher than $40 \mathrm{mM}$ a concentration plateau is achieved; in other 
words, because of the surface saturation the peak current density does not vary anymore increasing $\mathrm{C}_{\mathrm{T}}$.

Wopschall and Shain reported a theoretical treatment of the adsorption processes influences on the voltammetric response [19]. They stated that three important aspects should be considered as diagnostic criteria for adsorption processes: $(i)$ shape of the voltammetric response, (ii) qualitative relation between $\mathrm{j}_{\mathrm{p}} \cdot \mathrm{C}_{\mathrm{T}}{ }^{-1} \cdot \mathrm{v}^{-1 / 2}$ and $v$, and (iii) evaluation of the relation between of $\mathrm{j}_{\mathrm{p}} \cdot \mathrm{C}_{\mathrm{T}}{ }^{-1}$ and $\mathrm{C}_{\mathrm{T}}$. Particularly, the second criterion does not make sense since it was stayed for electrochemical reactions without kinetic complications and in the absence of coupled chemical reactions.

According to the theory, $\mathrm{j}_{\mathrm{p}} \cdot \mathrm{C}_{\mathrm{T}}^{-1}$ must increase with decreasing $\mathrm{C}_{\mathrm{T}}$ until achieving the concentration limit value $\left(\mathrm{C}_{\mathrm{Tlim}}\right)$ [19]. At lower concentration than $\mathrm{C}_{\mathrm{Tlim}}$, $\mathrm{j}_{\mathrm{p}} . \mathrm{C}_{\mathrm{T}}^{-1}$ should reach a constant value. In this region of low concentration, Henry's isotherm gives the relation between the surface concentration and solution concentration of active species [20]. On the other hand, for the Wopschall's statements other isotherms (i.e. Lagmuir's isotherm) should be considered at high concentration values.

Fig. $5 \mathrm{~b}$ shows the $\mathrm{j}_{\mathrm{p}} \cdot \mathrm{C}_{\mathrm{T}}{ }^{-1}-\mathrm{C}_{\mathrm{T}}$ relationship for the system under consideration. As it was predicted by the theory, $\mathrm{j}_{\mathrm{p}} \cdot \mathrm{C}_{\mathrm{T}}^{-1}$ tends to increase with decreasing $\mathrm{C}_{\mathrm{T}}$; however, at very low concentrations $(8 \mathrm{mM})$ this tendency is still kept. It must be highlighted that even at low toluene concentration some film is formed on the electrode surface, which deviates the behaviour predicted by the Henry's isotherm. At this condition two surface processes should be consider: $(i)$ toluene adsorption and (ii) deposition of the film on the surface.
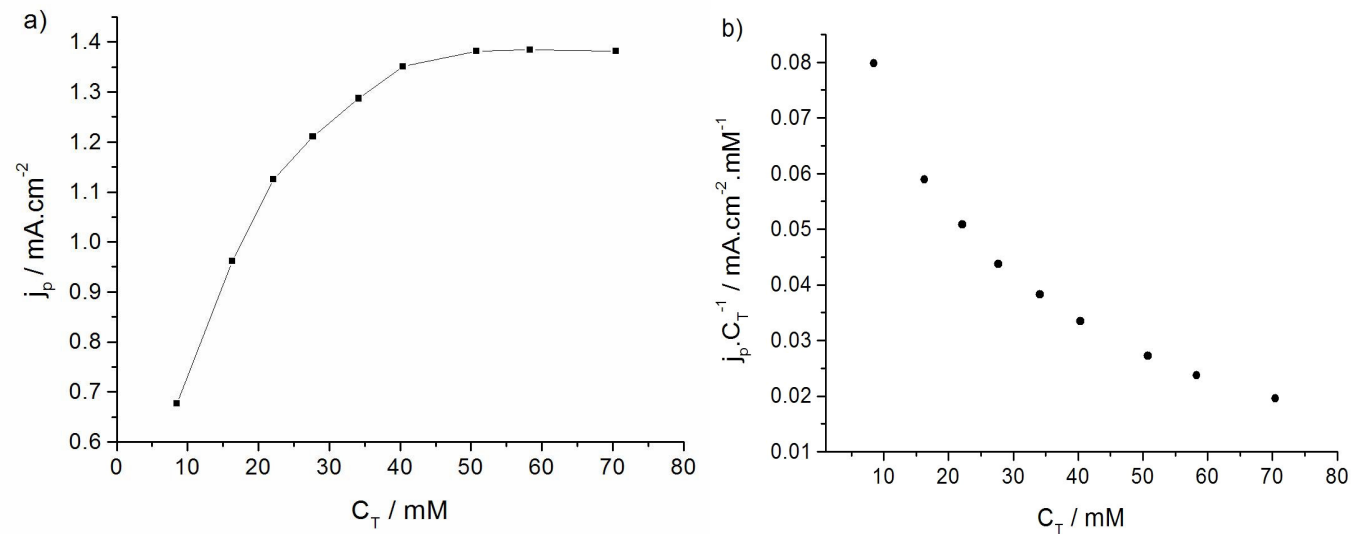

Figure 5. a) Variation of $j_{p}$ with the molar concentration of toluene $\left(C_{T}\right)$; b) $j_{p} \cdot C_{T}{ }^{-1}-C_{T}$ relationship.

b) Effect of water addition to the electrolytic medium on the electrochemical response

The electrochemical oxidation of toluene is strongly influenced by the water content of the electrolytic medium. Water additions produce very important cathodic displacements of the anodic peak potential (Fig. 6). 
These potential displacements indicate that toluene is more easily oxidized in water containing solutions. Water discharge reaction (wdr) starts at about 1500 $\mathrm{mV}$ on GC electrodes [13] concomitantly with toluene electro-oxidation; in other words, the electrochemical reaction of toluene could be assisted by wdr. The complete electrochemical reaction involves two steps: $i$ ) atomic oxygen species ([O]) produced by wdr [21] and electron charge transfer reaction of toluene (both reactions occurring at the same time), and $i$ ) reactions between the activated species produced in step $i$ ).

In a next article, part II, we will show details about the electro-oxidation of toluene in $30 \% \mathrm{~V} / \mathrm{V} \mathrm{CH}{ }_{3} \mathrm{CN}+1 \mathrm{M} \mathrm{H}_{2} \mathrm{SO}_{4}$ solutions (aqueous medium). In which, different electrochemical reaction aspects and products distribution were found.

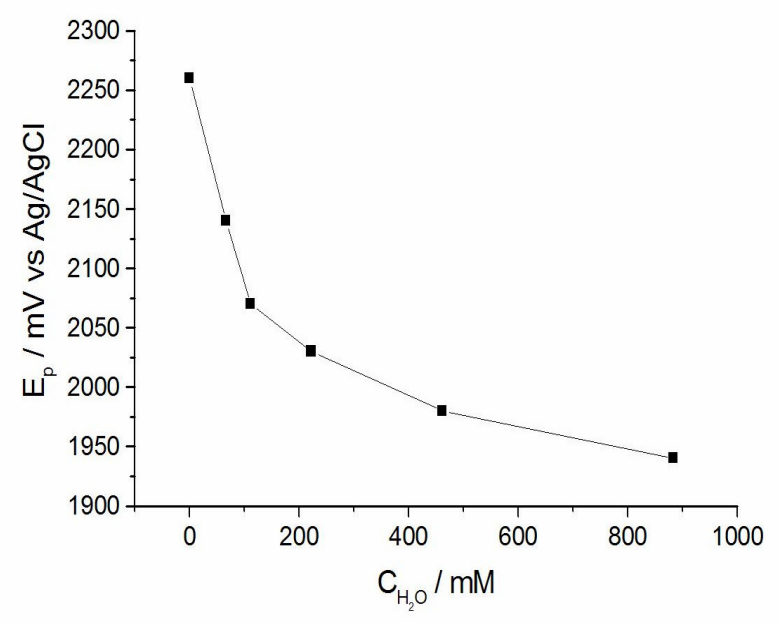

Figure 6. Effect of water additions to the electrolytic medium on $\mathrm{E}_{\mathrm{p}}$ values.

\section{Spectroelectrochemical studies. In situ FTIR}

Fig. 7 shows the Subtractive Normalized Fourier Transform Infrared (SNIFTIR) spectra of a GC electrode in the electrolytic medium at different potentials. Downward bands indicate apparition and upward bands suggest disappearance of chemical bonds. The most prominent bands at the spectra are summarized in Table 1 .

A group of downward and upward peaks situated between 2326 and $2240 \mathrm{~cm}^{-}$ ${ }^{1}$ correspond to the $\mathrm{CH}_{3} \mathrm{CN}$ vibrations. The upward peaks are produced by the $\mathrm{CH}_{3} \mathrm{CN}$ leaky from the thin layer, specifically due to the nitrile $(\mathrm{C} \equiv \mathrm{N})$ stretching vibration. $\mathrm{C} \equiv \mathrm{N}$ species are transformed to other ones with very similar nature, which produce downward peaks displaced to the blue. These bands are the result of electrostatic interaction between the positive charged electrode surface and the free electrons of the nitrogen atom [22,23].

Three new upward bands situated at 3638, 3546 and $1621 \mathrm{~cm}^{-1}$ are observed when potentials higher than $2000 \mathrm{mV}$ were applied. These are due to the $\mathrm{H}_{2} \mathrm{O}$ vibrations in the complex $\mathrm{CH}_{3} \mathrm{CN} .1 / 2 \mathrm{H}_{2} \mathrm{O}$ [24] and indicates that the $\mathrm{CH}_{3} \mathrm{CN} .1 / 2 \mathrm{H}_{2} \mathrm{O}$ leaky from the thin layer. It was already stated that the used 
$\mathrm{CH}_{3} \mathrm{CN}$ has $3 \mathrm{mM}$ of water concentration, which explains the behaviour reported before.

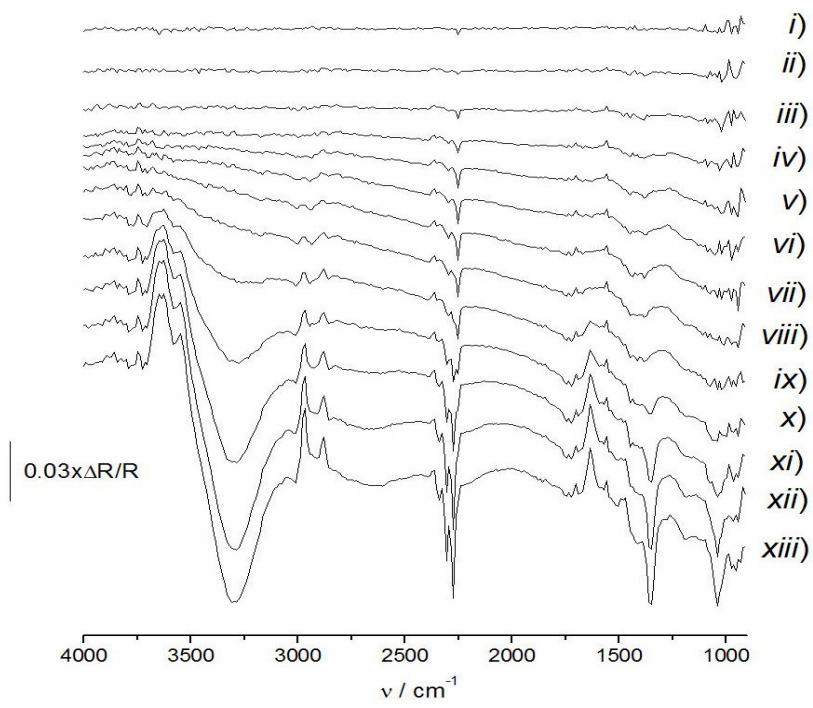

Figure 7. SNIFTIR spectra of a $\mathrm{GC}$ electrode in $0.1 \mathrm{M} \mathrm{But}_{4} \mathrm{NPF}_{6}+\mathrm{CH}_{3} \mathrm{CN}$. Spectra were collected at: i) $200 \mathrm{mV}$; ii) $400 \mathrm{mV}$; iii) $600 \mathrm{mV}$; iv) $800 \mathrm{mV}$; v) $1000 \mathrm{mV}$; vi) $1200 \mathrm{mV}$; vii) $1400 \mathrm{mV}$; viii) $1600 \mathrm{mV}$; ix) $1800 \mathrm{mV}$; x) $2000 \mathrm{mV}$; xi) $2200 \mathrm{mV}$; xii) $2400 \mathrm{mV}$ and $x$ iii) $2600 \mathrm{mV}$. Reference potential: $0 \mathrm{mV}$.

Table 1. Most relevant bands at the SNIFTIR spectra showed in Fig. 7.

\begin{tabular}{|c|c|c|}
\hline Type of band & Wave number $/ \mathrm{cm}^{-1}$ & Comments \\
\hline Upward & 3638 & O-H stretching ${ }^{\mathrm{a}}$ \\
\hline Upward & 3546 & O-H stretching ${ }^{\mathrm{a}}$ \\
\hline Upward & 1621 & O-H deformation ${ }^{\mathrm{a}}$ \\
\hline Upward & 2970 & $\mathrm{Csp}^{3}-\mathrm{H}$ stretching ${ }^{\mathrm{b}}$ \\
\hline Upward & 2880 & $\mathrm{Csp}^{3}-\mathrm{H}$ stretching ${ }^{\mathrm{b}}$ \\
\hline Downward & 3298 & $\mathrm{PF}_{6}^{-\mathrm{c}}$ \\
\hline Downward & 1344 & $\mathrm{PF}_{6}^{-}$ \\
\hline Downward & 1035 & $\mathrm{PF}_{6}^{-}$ \\
\hline Upward & $(2326-2240)$ & $\mathrm{C} \equiv \mathrm{N}$ stretching ${ }^{\mathrm{a}}$ \\
\hline Downward & $(2326-2240)$ & $\mathrm{C} \equiv \mathrm{N}$ stretching ${ }^{\mathrm{d}}$ \\
\hline Downward & 2342 & $\mathrm{CO}_{2}$ asymmetric stretching \\
\hline
\end{tabular}

${ }^{\mathrm{a}} \mathrm{CH}_{3} \mathrm{CN} .1 / 2 \mathrm{H}_{2} \mathrm{O}$ complex, ${ }^{\mathrm{b}}\left(\mathrm{CH}_{3} \mathrm{CH}_{2} \mathrm{CH}_{2} \mathrm{CH}_{2}\right)_{4} \mathrm{~N}^{+},{ }^{\mathrm{c}} \mathrm{PF}_{6}-\ldots . \mathrm{H}_{2} \mathrm{O}$ complex, ${ }^{\mathrm{d}}$ Electrostatic interaction between the electrode surface and the free electrons of the nitrogen.

Applying $2200 \mathrm{mV}$ and higher potentials, a downward peak at $2342 \mathrm{~cm}^{-1}$ indicates the formation of $\mathrm{CO}_{2}$ from $\mathrm{CH}_{3} \mathrm{CN}$ decomposition. It may be noted that the low intensity of the band is due to the small quantity of $\mathrm{CO}_{2}$, since the reaction is kinetically unfavorable at GC surfaces [25].

Finally three downward peaks located at 3298, 1344 and $1035 \mathrm{~cm}^{-1}$ are attributed to the entrance of $\mathrm{PF}_{6}^{-}$to the thin layer. On the other hand, two upward bands 
close to $3000 \mathrm{~cm}^{-1}$ are associated to the $\mathrm{But}_{4} \mathrm{~N}^{+}$leaky from the thin layer by simple electrostatic repulsion.

Compared to Fig. 7, Fig. 8 clearly shows that toluene addition does not bring so many changes to the SNIFTIR spectra. Only two new downward peaks located at 1699 and $1725 \mathrm{~cm}^{-1}$ are observed. Both of them, could be assigned to the vibrations of $\mathrm{C}-\mathrm{C}$ and $\mathrm{C}=\mathrm{C}$ (extended aromatic systems) bonds, respectively. Therefore, it is strongly suggested that the formation of products involves the coupling of toluene molecules to yield dimmers, trimmers and olygomers. These compounds are the principal precursors of the polymerization reaction or the film formation process.

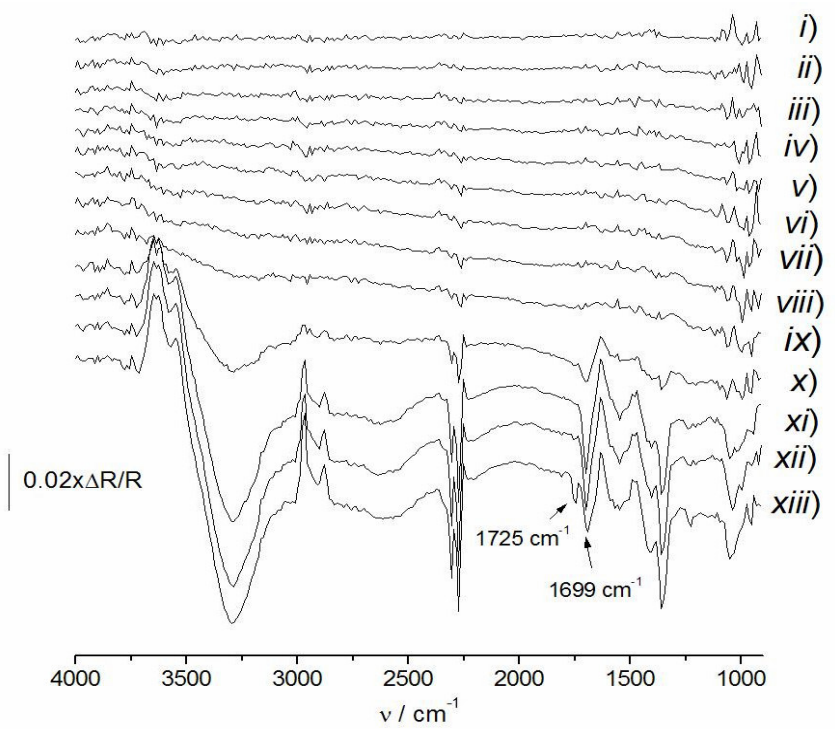

Figure 8. SNIFTIR spectra of a GC electrode in $0.1 \mathrm{M}$ Toluene $+0.1 \mathrm{M} \mathrm{But}_{4} \mathrm{NPF}_{6}+$ $\mathrm{CH}_{3} \mathrm{CN}$. Spectra were collected at: i) $200 \mathrm{mV}$; ii) $400 \mathrm{mV}$; iii) $600 \mathrm{mV}$; iv) $800 \mathrm{mV}$; v) $1000 \mathrm{mV}$; vi) $1200 \mathrm{mV}$; vii) $1400 \mathrm{mV}$; viii) $1600 \mathrm{mV}$; ix) $1800 \mathrm{mV}$; x) $2000 \mathrm{mV}$; xi) $2200 \mathrm{mV}$; xii) $2400 \mathrm{mV}$ and xiii) $2600 \mathrm{mV}$. Reference potential: $0 \mathrm{mV}$.

\section{Conclusions}

The electrochemical oxidation of toluene depends on the experimental time scale and involves different steps or reactions that could control the global transformation. At low sweep rates the reaction is controlled by the pure charge transfer reaction, but at high sweep rates the adsorption of toluene defines the electro-oxidation reaction. Additionally, the electrochemical reaction is followed by a chemical reaction (EC mechanism) that yields the polymeric film deposited on the electrode surface. In situ FTIR tests reinforced this fact. According to the applied potential, the coupling of toluene molecules promotes the formation of olygomers and therefore the polymeric film deposition.

\section{Acknowledgements}

Luis F. D'Elia would like to thank to PDVSA Intevep (Filial de Petróleos de Venezuela, PDVSA) for the financial support and technical assistance. 


\section{References}

1. K. Rajeshwar, J.G. Ibañez, Environmental Electrochemistry: Fundamentals and Applications Abatement, Academic Press, London, 1997.

2. C. Bock, B. MacDougall, J. Electroanal. Chem. 491 (2000) 48.

3. L.F. D’Elia, R.L. Ortíz, O.P. Márquez, J. Márquez, Y. Martínez, J. Electrochem. Soc. 148 (2001) 297.

4. M.M. Baizer, H. Lund, Organic Electrochemistry: An Introduction and a Guide, Marcel Dekker, New York, 1990.

5. $\quad$ S. Park, R.J. Gorte, J.M. Vohs, Appl. Catal. A: General 200 (2000) 55.

6. $\quad$ S. Park, M. Vohs, R.J. Gorte, Nature 404 (2000) 265.

7. J.W. Loveland, G.R. Dimeler, Anal. Chem. 33 (1961) 1196.

8. $\quad$ N.L. Weinberg, H.R. Weiberg, Chem. Rev. 68 (1968) 449.

9. S.W. Feldberg, J. Am. Chem. Soc. 88 (1966) 390.

10. D.E. Couch, Electrochim. Acta 9 (1964) 327.

11. S.E. Treimer, J. Feng, M.D. Scholten, D.C. Johnson, A.J. Davenport, J. Electrochem. Soc. 148 (2001) E-459.

12. L.F. D'Elia, L. Rincón, R. Ortíz, Electrochim. Acta 49 (2004) 4197.

13. L.F. D'Elia, L. Rincón, R. Ortíz, Electrochim. Acta 50 (2004) 217.

14. R.J. Gale, Spectroelectrochemistry. Theory and Practice, Plenum Press, New York, 1988.

15. N.M. Pontikos, R.L. McCreery, J. Electroanal. Chem. 324 (1999) 229.

16. A. Bard, R. Parson, J. Jordan, Standard Potential in Aqueous Solution, Marcel Dekker, New York, 1985.

17. Southampton Electrochemistry Group, Instrumental Methods in Electrochemistry, $1^{\text {st }}$ ed., Ellis Horwood, London, 1985.

18. M.S. Ureta-Zarñartu, P. Bustos, C. Berríos, M.C Diez, M.L. Mora, C. Gutiérrez, Electrochim. Acta 47 (2002) 2399.

19. R.H. Wopschall, I. Shain, Anal. Chem. 39 (1967) 1514.

20. E. Gileadi, E. Kirowa-Eisner. J. Penciner, Interfacial Electrochemistry. An Experimental Approach, Addison-Wesley, Boston, 1988.

21. Y. Yang, G. Ling, J. Appl. Electrochem. 25 (1995) 259.

22. T. Davidson, B.S. Pons, A. Bewick, P.P. Schmidt, J. Electroanal. Chem. 125 (1981) 242.

23. S. Pons, T. Davidson, A. Bewick, J. Electroanal. Chem. 160 (1984) 63.

24. S. Pons, T. Davidson, A. Bewick, J. Electroanal. Chem. 140 (1982) 211.

25. P. Krtil, L. Kavan, P. Novák, J. Electrochem. Soc. 140 (1993) 3390. 